\title{
Analysis on the Present Situation and Countermeasures of Chinese Table Tennis
}

\author{
Xiao-Cao XIA \\ Jiangxi Normal University \\ Nanchang \\ E-mail: 1219822060@qq.com
}

\author{
De-Ming YANG \\ Jiangxi Normal University \\ Nanchang \\ E-mail: jxsdtywml@163.com
}

\begin{abstract}
Table tennis has a long history, from the initial twentieth Century European prosperity to the Eurasian eye, and finally to the current situation of China dominate the world table tennis table tennis. China experienced many groundless talk. From 1995, China table tennis team in the world championships in Tianjin, Chinese table tennis stability in the world leading level. And in the 08 year of the Olympic Games and 12 years of Olympic Games, there is no doubt that the China table tennis team to win a grand slam, stood on the top of table tennis. We cheered the victory at the same time, have caused the unbalanced thinking. Table tennis is bound to the development of world table tennis has a negative impact on the development of the China. A thriving, in addition to the unbalanced development of world table tennis, table tennis China development also appeared in many problems. In this paper, according to the present situation of Chinese table tennis development were analyzed, and put forward the corresponding countermeasures.
\end{abstract}

\section{Keywords-table tennis; development; dilemma; countermeasure}

\section{PREFACE}

Table tennis has a long history began in the second half of the 19th century British, the first to flourish in Europe. 1926 first World Table Tennis Championships to 1951 the 18th World Table Tennis Championships. European countries have made a lot of gold medals in the World Table Tennis Championships. Until 1952, Japan invented the long pumping of the play, defeated Europe. Eight years won the 24 World Table Tennis Championships, in the world leading level. While China from the 25th World Table Tennis Championships first championship to the 26th World Table Tennis Championships three championships. Gradually began the Chinese table tennis championship road. Between 1971 and 1987, China won two-thirds of the International Competition, at the leading level in the world at this time. European countries have experienced Japan and China up to 20 years after the repression, gradually out of the woods. In China's fast break and the Japanese circle on the basis of the ball invented for Europeans new play. At this time the emergence of a group of high-level players in Europe, such as: Croatian players Zoran. Primula times, Sweden's Waldner. Making the world table tennis formed Eurasian confrontation situation. In 1989 to 1933 Chinese table tennis entered the downturn. But soon in 1995 to regain the world championship. Since then, the Chinese table tennis into the era of flourishing. Stable at the world's leading level. Whether it is the Olympic Games, the World Cup, or a variety of table tennis tournament, our athletes basic swept the trophy. In China's monopoly, the development of table tennis unbalanced lead to the development of table tennis there are many problems.

\section{The Present Situation And Dilemma OF TABLE TENNIS}

\section{A. From the "Overseas Corps" to "Wolf Plan", China for the Development of the World Table Tennis Efforts in the Effort}

'Under the national system' under the advantages of China's talent in the project led to excessive internal competition extremely fierce and brutal. This makes many excellent athletes and coaches do not have the opportunity to fulfill their dreams, but in some low-level table tennis countries naturally become their carrier of personal values and dreams. To join other countries nationality, choose 'overseas corps' to become their best trouble to break through the dilemma. At the same time, our athletes are special groups in society. In real life, they restrict the development of cultural knowledge in order to improve athletic ability and athletic performance. After retiring, they cannot possess the social ability of cultural knowledge to survive. An athlete with basic living security and security needs cannot be achieved. In this scenario, the favorable conditions provided by the developed countries in all aspects have become an important factor for many outstanding athletes to go to 'overseas corps'. 'Overseas Corps' to join, a substantial increase in many countries in the table tennis international competition results. In the 2008 International Table Tennis Tour the first leg of the Slovenian Open, on behalf of the Netherlands participating in the "overseas corps" Li Jiao won the championship; Italian nationality "overseas corps" Tan Wenling in 2003 won the 24th European table tennis tournament women's team champion; Origin of China's Liaoning, after the naturalization of Japan's Han Yang won the 2007 ITTF 
career tour Brazil and Chile two race men's singles champion. 'Overseas Corps' created by the excellent results brought not only the heavy medals, as well as foreign groups, especially young people on the table tennis voluntariness, participation, penetration, increased table tennis reserve talent. After the formation of a virtuous circle, it is advantageous for the importing country to cultivate the "native player" in the true sense, thus promoting the good and sustainable development of the table tennis. "Overseas corps" to the table tennis has brought many beneficial effects, but cannot be denied that there are other negative effects. Although the "overseas corps" to improve the performance of many countries table tennis, to the country brought a lot of glory, but to combat the enthusiasm of local players involved. Resulting in the local players cannot beat overseas corps, the game did not participate in local players, or even no local players to participate. Such a vicious phenomenon will certainly constrain the development of table tennis in these countries. Many local players for the "overseas Corps" made a protest. So on September 1, 2008 began the implementation of the table tennis "overseas Corps" restraining order introduced: 21 years old players to represent the "new owner" to participate in the World Table Tennis Championships or the World Cup, must be settled in the country, and in the Association Registered for 7 years. Part of the young people who want to go abroad thinking will be considered in advance of the relevant issues, which will cause a large number of Chinese table tennis reserve talent loss, long term will affect the sustainable development of Chinese table tennis. And although the implementation of the restraining order on the surface limits the "overseas Corps" members of the increase, but did not fundamentally solve the "international competition is the Chinese people take medals" problem.

"Overseas Corps" after the basic failure of this way, in 2009, as a Ping-Pong power China for the current world table tennis unbalanced present situation put forward "go out, please come in" approach is our popular "wolf plan." To improve the technical level of overseas table tennis players, which helps the long-term development of table tennis. The main way is to allow more coaches and athletes to go abroad to communicate, or to allow foreign athletes to train in China to help them improve the level of narrowing the gap between Chinese athletes and foreign athletes. To assist the ITTF to carry out more activities, and strive to make the league more international. "Wolves Plan" is a long-term implementation of the plan, is indeed feasible. But the degree of the wolf is very important, not to say that China would like to raise the wolf can be developed, China is only a leading role, but also the International Table Tennis Federation and the world's countries and associations to complete this great project.

\section{B. China's "One Big One" to the Table Tennis Project Brought the Olympic Crisis}

For a long time, due to the strong Chinese table tennis, the participation of European and American countries in this project has been reduced to the freezing point, which also led to the sport of the table in the international sports status and influence of increasingly weak. In order to weaken the strength of Chinese table tennis, so that other countries have the opportunity to players and Chinese athletes' confrontation, and achieved good results. ITTF in the continuous competition rules reform: change the ball, 21 points system to 11 points system, the implementation of non-blocking serve and so on. However, these reform measures for the Chinese table tennis team has little effect, but the impact of other national players to play. In recent years, the international competition, we will find that the game called to play, and finally all the Chinese athletes, many countries have made the results or change the nationality of Chinese athletes. If a game item loses its competitiveness and loses the world's attention to it, it is likely to face a "kick out" of the Olympics. The IOC has such a rule that if a sport project is not well popular in more than 70 countries around the world, there will be some necessary consideration to abolish the qualification of the sport in the Olympic Games. For example, in 2005, the International Olympic Committee (IOC) held a vote on 28 items in the 2012 Olympic Games at the 117th plenary session in Singapore. If the existing project is to remain in the Olympic Games, more than 110 members must be given at least half the number of votes. The result of the vote was that baseball, which had a broad mass base in the United States and Japan, was swept out, for the simple reason that the popularity in the world was too low. Baseball's "tragic" fate makes people have to worry about the prospect of table tennis in the Olympic Games.

\section{There is No Suspense in the Table Tennis Tournament to Cause the Audience to lose a lot.}

The status quo of Chinese table tennis stabilized voucher, has also become a healthy development of Chinese table tennis industry a major resistance. The competition is full of competition and challenges of the sporting events have become no surprise, table tennis tournament no suspense greatly reduced the fans of the enthusiasm of this sport. The face of the Chinese table tennis swept the championship phenomenon, the enthusiasm of the audience is increasingly reduced. Table tennis tournament CCTV broadcast rate and the attendance rate of the scene year after year decline can explain the audience for the table tennis tournament attention continues to decline. In March 3, 2016 to March 10 held in Shenzhen Gymnasium on the surface of the strongest 12 people 2017-2020 through Tokyo Guobang through race. This is the cooperation between the China Table Tennis Association and Tencent, in the "through race" in the name of the first 11 years after the first direct broadcast to the Internet platform, with the Rio Olympic Games red wind, so that the event to attract people's attention. The Tokyo Olympic Games as a gimmick through the race name. In the foot basket and other big market-oriented road in full swing in the occasion, Guoping this Chinese "ace of the division" is also looking for market-oriented direction, this pass is a national watch a move. The entire 10 days from the game throughout the live network, just in the last day of the "bloody battle" in the game by the Qinghai Satellite TV exclusive live. From the 
live we only see the Audi car and double happiness billboards, and the rest are the parties (table tennis) advertising, compared to basketball and other items in the event of advertising implantation, the number of ad ads It is less pitiful. This clearly shows the lower commercial value. At the same time although the audience attention is not high, but cannot forget the lack of advertising operations. Zhang Jike announced the day of injury due to retire, the court less a half fans. This shows that the audience is not to see the game, but to see the stars Bale. Through these phenomena show that the table tennis tournament is no suspense, accompanied by the ornamental, ratings, attendance and business value greatly reduced. China's table tennis industry has a long way to go.

\section{CONCLUSION AND SUGgESTION}

\section{A. Conclusion}

1. Chinese table tennis team in the major international events on the outstanding achievements, so that the state, the people have added a lot of sense of honor and pride, but also greatly promoted China's political, economic and cultural rapid development.

2. In the world of unbalanced development of table tennis, as a table tennis power, to take up the responsibility of the people in order to improve the promotion of table tennis culture and development, and promote the globalization of table tennis to contribute.

3. "Overseas Corps" did not fundamentally solve the problem of unbalanced development of the world's bracelet, and the proposed "wolf plan" in the implementation process also has many difficulties.

\section{B. Suggestion}

1. Chinese table tennis to adapt to the development trend of world table tennis, table tennis in the international sports on the road to eliminate the hidden dangers.

2. China Table Tennis Association can learn from the United States NBA and European Football League development concept, need to find a suitable for table tennis sports business model, so that the sports industry has become a strong driving force of table tennis. For the development of sports table tennis and public table tennis to provide fertile soil.

3. To further improve the 'wolf plan', to strengthen domestic and foreign athletes and coaches exchanges. To promote other countries and regions of table tennis technology and China's common development.

\section{REFERENCE}

[1] He Yuanchun. Value cognition of Chinese table tennis in cultural interaction [J]. Journal of Beijing Sport University, 2011,2 (34): 24-29

[2] Zhang Yunxia. Research on current situation and Countermeasures of world table tennis development [D]. Wuhan Sports Institute, 2012

[3] Wang Jinyu. Influence of Overseas Corps on the development of table tennis. [D]. Jilin Institute of Physical Education, 2010

[4] Jiang Wei. Some thoughts on the success of Chinese men's table tennis team [J]. Journal of Guiyang University, 2016,11 (6): 135-137

[5] Zhang Yi. Study on the pattern of world table tennis history and development of J. The sports world, 2016,1 (1): 12-14

[6] Wang Ke. "Chinese of table tennis development strategy of a dominant" -- Based on the analysis of the fifty-first Rotterdam World Championships J. Hubei sports science and technology, 2011,30 (6) 660-662 